\title{
Self-Serving Bias and Tax Morale
}

\author{
Kay Blaufus
}

Matthias Braune

Jochen Hundsdoerfer

Martin Jacob

\section{School of Business \& Economics}

Discussion Paper

\section{FACTS}

$2014 / 18$ 


\title{
Self-Serving Bias and Tax Morale
}

\author{
Kay Blaufus \\ Leibniz University Hannover \\ blaufus@steuern.uni-hannover.de \\ Matthias Braune \\ Freie Universität Berlin \\ matthias.braune@fu-berlin.de \\ Jochen Hundsdoerfer \\ Freie Universität Berlin \\ jochen.hundsdoerfer@fu-berlin.de \\ Martin Jacob \\ WHU - Otto Beisheim School of Management \\ martin.jacob@whu.edu
}

This version: September 2014

\begin{abstract}
In a real-effort laboratory experiment to manipulate evasion opportunities, we study whether the moral evaluation of tax evasion is subject to a self-serving bias. We find that tax morale is egoistically biased: Subjects with the opportunity to evade taxes judge tax evasion as less unethical as opposed to those who cannot evade. The detection probability does not affect this result. Further, we do not find moral spillover effects, for example, on legal activities.
\end{abstract}

\section{Keywords}

Evasion · Tax Morale $\cdot$ Tax Compliance $\cdot$ Self-Serving Bias $\cdot$ Moral Spillover

\section{JEL Classification}

$\mathrm{H} 20 \cdot \mathrm{H} 26$ 


\section{Introduction}

Is morally right what benefits oneself? We analyze if moral evaluations of tax evasion are egoistically biased. Several researchers have emphasized the importance of tax morale in explaining observed tax evasion (e.g., Baldry 1986, Cummings et al. 2009). Tax morale is a special form of solidarity behavior with a low level of social interaction and interpersonal coordination (Brosig-Koch et al. 2011). It is often described as the intrinsic willingness to pay taxes (Alm and Torgler 2006, Russo 2013).

Typically, tax morale is assumed to arise independently of the individuals' economic situation. For example, there is almost no evidence of self-serving bias in Dahl and Ransom's (1999) survey of Mormon Church members about their voluntary contributions to the church. The authors, thus, conclude that subjects are able to separate out their own self-interest when forming ethical beliefs. The results might not be generalizable because religiousness is positively correlated with tax morale (Torgler 2006). In contrast, Blanthorne and Kaplan (2008) find evidence that "high-opportunity" taxpayers (business owners and earners of cash income without third-party reporting) judge underreporting as less unethical compared to "low-opportunity" taxpayers (all others). This result indicates that tax morale is subject to a self-serving bias. However, the authors' result might suffer from sample selection: Taxpayers with low tax morale can self-select into high-opportunity occupations.

It is, therefore, empirically unclear whether tax morale arises independently of individuals' economic situation or whether there is self-serving bias. In a real-effort lab experiment with a diverse subject pool and high variance in tax morale, we randomize subjects to treatments with and without tax minimization opportunities, to avoid sample selection bias. We demonstrate empirically that individuals' tax morale is subject to a self-serving bias. Individuals with the opportunity to evade taxes consider tax evasion less unethical compared to those without this opportunity. Our results are robust to different detection probabilities and economically similar but licit avoidance opportunities. We also find no spillover effects of evasion opportunities on other moral evaluations (e.g., bribery or lying).

\section{Hypothesis Development}

Previous tax compliance research often assumes that subjects' tax morale arises independently from economic considerations (Wenzel 2004). However, the construct 
tax morale itself could be affected by subjects’ economic environment. Psychological research indicates that peoples' fairness perceptions are influenced by self-serving bias. Subjects rate outcomes as fair if they benefit from the outcome (Messick and Sentis 1979). People like to think of themselves as honest (Mazar et al. 2008). One way to maintain a positive self-view is rationalization, an important determinant of fraud in criminology. Another way to maintain a positive self-view is to adjust (unconsciously) one's own moral evaluation of a specific deviant act, for example, tax evasion. Individuals can then reduce any cognitive dissonance from differences between moral attitude and actual behavior (Festinger 1957). The observed result would be an egocentric interpretation of tax morale (self-serving bias). Accordingly, we formulate our hypothesis as follows.

Hypothesis: The individual's opportunity to evade taxes decreases tax morale.

\section{Experimental Design}

We randomly assigned the subjects, 187 students of the XXX University, to one of three treatments (between-subject design). In all treatments, subjects were offered the same real effort task. Subjects had to key in paper test sheets from a modified multiple-choice test. The gross wage was $10 \mathrm{ECU}(1 \mathrm{ECU}=0.07 €)$ per correctly recorded sheet. After a training period, subjects chose the number of sheets to key in (between zero and 48). This labor supply decision was binding: Each subject had to key in the stated amount of sheets to receive the remuneration above the show-up fee of $5 €$. All subjects provided the self-determined level of labor supply.

Earned income was subject to progressive taxation. Subjects were informed that tax revenues increased the budget of the business school at the XXX University. The first four sheets were tax exempt, the fifth (and subsequent) sheet was taxed at a marginal tax rate of $30 \%$, and the 29th (and subsequent) sheet was taxed at $65 \%$.

Treatments differed only in the opportunity to evade taxes. In the No Opportunity treatment, subjects could not reduce their tax burden by tax evasion. In the Safe Opportunity as well as the Risky Opportunity treatments, subjects were instructed that they could illegally reduce their tax burden through tax evasion. Simultaneously with their labor supply decision, subjects could choose their level of tax evasion, with a maximum tax base reduction of six sheets. Subjects in the Safe Opportunity (Risky Opportunity) treatment were informed that tax evasion would not be detected (would be 
detected with a probability of $25 \%$ and that subjects would have to pay the evaded tax and a penalty of $50 \%$ of the evaded tax upon detection).

After subjects made their labor supply decisions and, in the two opportunity treatments, their tax evasion decisions, we asked them about their moral evaluations of five situations:

- Claiming state benefits to which one is not entitled,

- Cheating on taxes if one had the chance,

- Lying in one’s own interest,

- Accepting a bribe in the course of one's duties,

- Avoiding taxes by using legal means if given the chance.

The first four questions were taken from the 2008 European Values Survey. Since the European Values Study does not include a question about legal tax avoidance, we adapted the formulation from the tax evasion question. Subjects indicated on a Likert scale from one ("never justified") to 10 ("always justified”) how they evaluated each situation. To simplify interpretation, we recoded the variables by subtracting the answers from 11, such that a value of 10 (one) implies a high (low) morale.

In line with previous research (Alm and Torgler 2006, Doerrenberg and Peichl 2013), we use the answer to the tax evasion question as a measure of tax morale. The other four moral variables are used to study if evasion opportunity triggers a spillover effect on the moral evaluation of other activities. The experiment was programmed and conducted with the software z-Tree (Fischbacher 2007). After having completed a postexperimental questionnaire and having provided their labor supply, participants were remunerated in cash. On average, they received $19.07 €(\mathrm{SD}=4.28 €)$. The average duration of the experiment was 1 hour and 50 minutes.

\section{Results}

\subsection{Tax Morale}

Figure 1 presents average tax morale for all three treatments. In the No Opportunity treatment subjects, average tax morale is 8.15. Having evasion opportunities reduces tax morale to 7.41 (Safe Opportunity) and 7.34 (Risky Opportunity), respectively. The differences between No Opportunity treatment and each other treatment are significant (Safe Opportunity, $\mathrm{p}=0.069$; Risky Opportunity, $\mathrm{p}=0.049$, Mann-Whitney U-tests). This result is in line with our hypothesis: Subjects' tax morale is egocentrically biased and 
negatively affected by their own evasion opportunities. This holds for both riskless and safe evasion opportunities. We observe no significant difference between safe and risky opportunity treatments ( $\mathrm{p}=0.902$, Mann-Whitney U-test). All results hold if we control for sociodemographic variables such as gender, age, income, and study major in ordered probit models. ${ }^{1}$

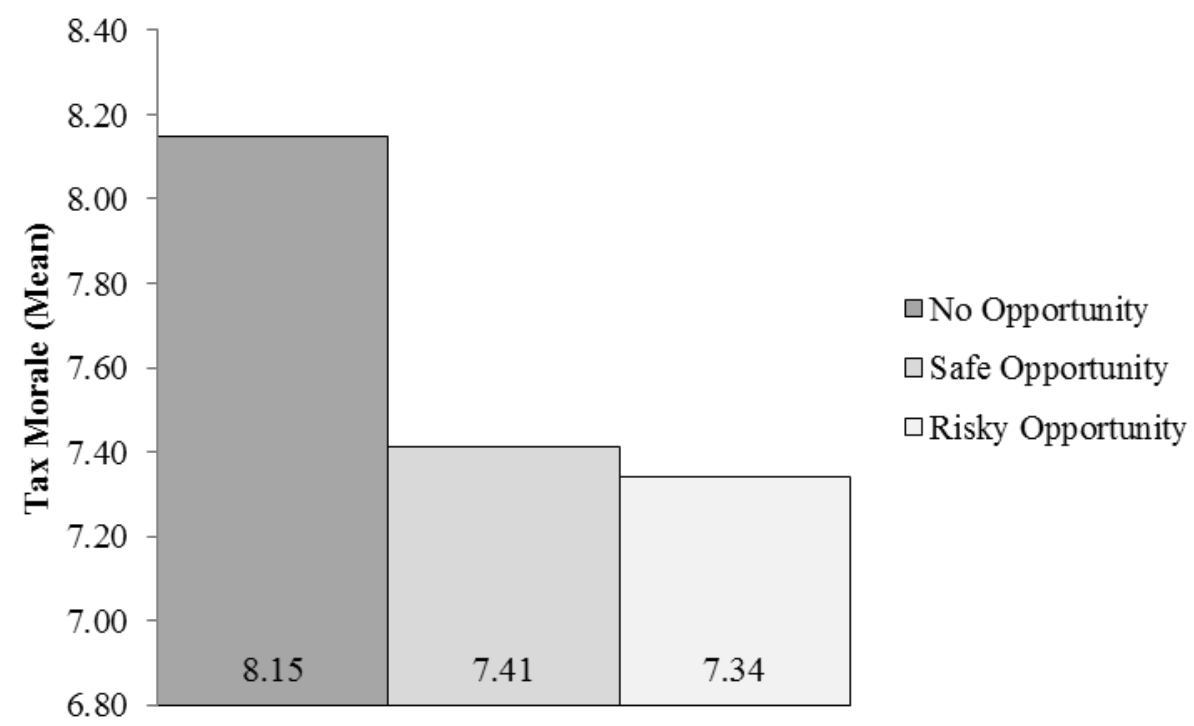

Figure 1: Average tax morale, measured on a 10-point-Likert scale (1 = low morale, 10 = high morale).

\section{$4.2 \quad$ (No) Spillover Effects}

Research on moral spillover shows that events that violate one's own moral standards can increase one’s deviant behavior in other areas (e.g., Mullen and Nadler 2008, Cornelissen et al. 2013). These observations suggest that introducing evasion opportunities could affect moral evaluations of other "misdoings." Table 1 displays the results of subjects' moral evaluations for the No Opportunity treatment and the two treatments with evasion. We aggregate the Safe Opportunity and Risky Opportunity treatments, since there are no significant differences between them. However, we do not find any evidence for a spillover effect. Thus, subjects only adjust their tax morale but do not alter other moral values.

\footnotetext{
${ }^{1}$ The results are available from the authors upon request.
} 
Table 1: Evasion Opportunity and Moral Evaluations

\begin{tabular}{lccccccc}
\hline & \multicolumn{2}{c}{$\begin{array}{c}\text { No Opportunity } \\
\text { (N=6) }\end{array}$} & \multicolumn{4}{c}{$\begin{array}{c}\text { Safe and Risky } \\
\text { Opportunities } \\
\text { (N=127) }\end{array}$} & Signif. \\
& Mean & Median & SD & Mean & Median & SD & p-values \\
\hline Tax Morale & $\mathbf{8 . 1 5}$ & $\mathbf{9 . 0 0}$ & $\mathbf{1 . 9 4}$ & $\mathbf{7 . 3 8}$ & $\mathbf{8 . 0 0}$ & $\mathbf{2 . 2 8}$ & $\mathbf{0 . 0 2 9}$ \\
\hline Claiming unjustified subsidies & 8.08 & 9.00 & 2.00 & 8.06 & 8.00 & 2.00 & 0.902 \\
Lying & 6.15 & 6.00 & 2.18 & 6.04 & 6.00 & 2.48 & 0.712 \\
Bribery & 8.73 & 9.00 & 2.01 & 8.36 & 9.00 & 2.23 & 0.375 \\
Tax avoidance & 2.90 & 2.00 & 2.41 & 2.65 & 1.00 & 2.46 & 0.204 \\
\hline
\end{tabular}

This table displays tax morale and other moral evaluations measured on a 10-point Likert scale $(1=$ low morale, 10 = high morale). The p-values are based on a Mann-Whitney U-test.

\subsection{Robustness}

One concern about our setting is that the No Opportunity and opportunity treatments differ in the actual tax burden. The fact that subjects can exploit tax evasion opportunities to reduce the tax burden might cause differences in observed tax morale. To control for this potential bias, we run two additional treatments with legal tax avoidance opportunities. These are equivalent to the safe and risky evasion opportunities, but we frame the tax reduction opportunity as a "legal tax loophole.” We find an average tax morale of 8.43 (8.37) in the safe (risky) avoidance opportunity treatment. This value is significantly larger than the tax morale observed in the corresponding evasion treatments $(\mathrm{p}=0.002$ in both comparisons, Mann-Whitney Utest) but not significantly different from the No Opportunity treatment ( $p=0.184$ and $\mathrm{p}=0.236$, respectively, Mann-Whitney U-test). Thus, we also observe a self-serving bias if we compare evasion opportunity treatments with economically equivalent avoidance opportunity treatments.

\section{Conclusion}

The present paper shows that moral evaluations of tax evasion are subject to a selfserving bias. Individuals with an evasion opportunity judge tax evasion as less unethical. We find no evidence for a spillover effect on moral evaluations of other misdoings. Our results suggest that the effect of moral appeals by policy makers on reducing tax evasion may not be as effective as expected due to self-serving bias. Moreover, our results might help explain why previous studies find lower tax morale among self-employed individuals (Alm and Torgler 2006). These are typically taxpayers with higher evasion opportunities and thus particularly prone to a self-serving bias. 


\section{References}

Alm, J., \& Torgler, B. (2006). Culture differences and tax morale in the United States and in Europe. Journal of Economic Psychology, 27(2), 224-246.

Baldry, J. C. (1986). Tax evasion is not a gamble: A report on two experiments. Economics Letters, 22(4), 333-335.

Blanthorne, C., \& Kaplan, S. (2008). An egocentric model of the relations among the opportunity to underreport, social norms, ethical beliefs, and underreporting behavior. Accounting, Organizations and Society, 33(7-8), 684-703.

Brosig-Koch, J., Helbach, C., Ockenfels, A., \& Weimann, J. (2011). Still different after all these years: Solidarity behavior in East and West Germany. Journal of Public Economics, 95(11), 1373-1376.

Cornelissen, T., Himmler, O., \& Koenig, T. (2013). Fairness spillovers-The case of taxation. Journal of Economic Behavior \& Organization, 90, 164-180.

Cummings, R. G., Martinez-Vazquez, J., McKee, M., \& Torgler, B. (2009). Tax morale affects tax compliance: Evidence from surveys and an artefactual field experiment. Journal of Economic Behavior \& Organization, 70(3), 447-457.

Dahl, G. B., \& Ransom, M. R. (1999). Does where you stand depend on where you sit? Tithing donations and self-serving beliefs. American Economic Review, 89(4), 703-727.

Doerrenberg, P., \& Peichl, A. (2013). Progressive taxation and tax morale. Public Choice, 155(3-4), 293-316.

Festinger, L. (1957). A Theory of Cognitive Dissonance. Evanston, IL: Row Peterson.

Fischbacher, U. (2007). z-Tree: Zurich toolbox for ready-made economic experiments. Experimental Economics 10(2), 171-178.

Mazar, N., Amir, O., \& Ariely, D. (2008). The dishonesty of honest people: A theory of self-concept maintenance. Journal of Marketing Research, 45(6), 633-644.

Messick, D. M., \& Sentis, K. P. (1979). Fairness and preference, Journal of Experimental Social Psychology, 15(4), 418-434.

Mullen, E., \& Nadler, J. (2008). Moral spillovers: The effect of moral violations on deviant behavior. Journal of Experimental Social Psychology, 44(5), 1239-1245.

Russo, F. F. (2013). Tax morale and tax evasion reports. Economics Letters, 121(1), $110-114$.

Torgler, B. (2006). The importance of faith: Tax morale and religiosity. Journal of Economic Behavior \& Organization, 61(1), 81-109.

Wenzel, M. (2004). The social side of sanctions: personal and social norms as moderators of deterrence. Law and Human Behavior, 28(5), 547-567. 


\section{Diskussionsbeiträge - Fachbereich Wirtschaftswissenschaft - Freie Universität Berlin Discussion Paper - School of Business and Economics - Freie Universität Berlin}

2014 bereits erschienen:

2014/1 FOSSEN, Frank M.; Ronny FREIER und Thorsten MARTIN

Race to the debt trap? : Spatial econometric evidence on debt in German municipalities

Economics

2014/2 SCHREIBER, Sven

Anticipating business-cycle turning points in real time using density forescasts from a VAR

Economics

2014/3 FOSSEN, Frank M. und Daniela GLOCKER

Stated and revealed heterogeneous risk preferences in educational choice Economics

2014/4 KNABE, Andreas, Ronnie SCHÖB und Marcel THUM

Der flächendeckende Mindestlohn

Economics

2014/5 QUINT, Dominic und Pau RABANAL

Monetary and Macroprudential Policy in an Estimated DSGE Model of the Euro Area

Economics

2014/6 HUGHES HALLETT, Andrew; Ansgar RANNENBERG und Sven Schreiber New Keynesian versus old Keynesian government spending multipliers: a comment

Economics

2014/7 DOBUSCH, Leonhard

Digitale Zivilgesellschaft in Deutschland : Stand und Perspektiven 2014

Management

2014/8 BEZNOSKA, Martin

Estimating a Consumer Demand System of Energy, Mobility and Leisure :

a Microdata Approach for Germany

Economics

2014/9 GÖRLITZ, Katja und Sylvi RZEPKA

Does Regional Training Supply Determine Employees' Training Participation?

Economics

2014/10 BRANDSTETTER, Laura

Do Corporate Tax Cuts Reduce International Profit Shifting?

FACTS 


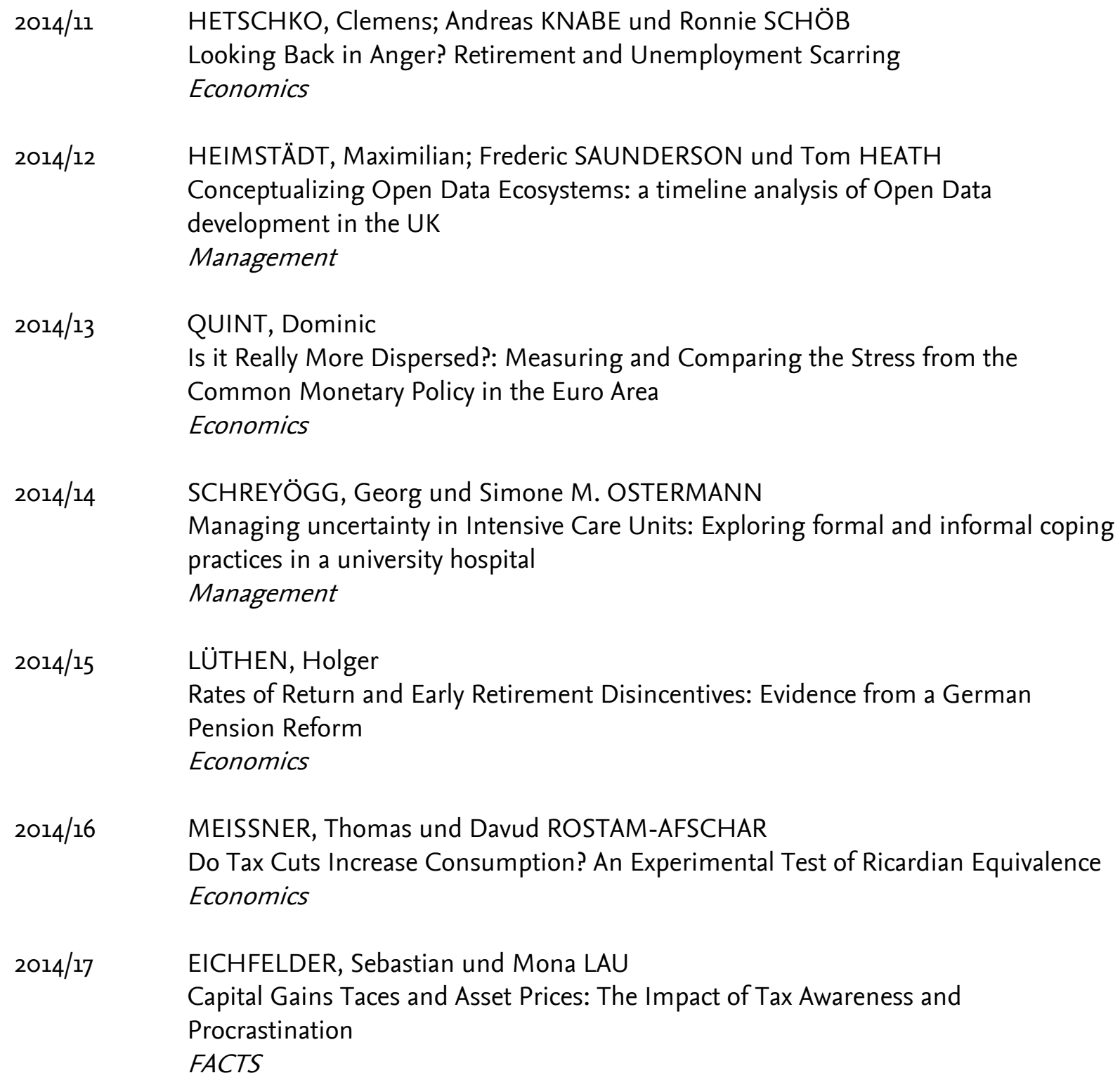

